\title{
Moral (and Other) Laboratories and the Semantic Impertinence of Metaphor: An Afterward
}

\author{
Cheryl Mattingly ${ }^{1}$
}

Published online: 2 May 2017

(C) Springer Science+Business Media New York 2017

It's a special pleasure to have to think again about one's own ideas because of the way others engage with them, or take detours from them, or turn them upside down. Even familiar concepts and images become strange when carried to ethnographic shores distant from one's own. So, I want to begin by thanking the contributors to this special issue for the surprises in these articles. In turning to them I have had to reflect more than once on the metaphor that framed Moral Laboratories. I clung to this rhetorical figure with a stubborn insistence when I was writing the book and giving talks about it, despite some very reasonable protests that a laboratory was a strange sort of trope to catch the unruly, chancy lives, haunted by moral tragedy and ethical uncertainty, that I was trying to illuminate. When I selected it as a defining image, I chose it in part for its misfit with the ethnographic spaces I was exploring which were grounded in a 15 year ethnography of African American families raising children with severe chronic illnesses and disabilities.

While the world of experimental medical science was one shadowy background scene for some of the families my colleagues and I followed, my exemplar of a moral laboratory was not this kind of space. Rather it was the one I opened my book with: a soccer field in which a boy in a wheelchair is playing in a neighborhood children's league, cheered on by parents standing on the sidelines. Soccer, in this instance, has to be locally reinvented by the children and parents. What are the rules of play with a wheelchair in the middle? To think about a soccer field as a laboratory was, I thought, a "semantic impertinence." I adopted this idea from the philosopher, Paul Ricoeur, and his framing of what metaphor has to offer. He argues that metaphor has the capacity to provide "untranslatable information." It is precisely

Cheryl Mattingly

cfmattingly@gmail.com

1 University of Southern California, Los Angeles, CA, USA 
through its resistance to literal translation that it may yields insights into reality, truths otherwise hard to see. A metaphor, as the literary theorist Beardsley (1962) pointed out, is a "logical absurdity." Of course, many of our common metaphors are dead; the absurdity has been lost on us. They have become literal through repeated use: "the foot of a mountain," comes to mind, or the "head" of the department. Or "chair" for that matter.

But if metaphors are alive, and if they strike the right kind of note, they can, as Ricoeur put it, "produce a new semantic pertinence by means of an impertinent attribution" (1984, p. ix; See also Ricoeur 2003 for his most elaborate discussion of this position). He goes on to state, "the metaphor is alive as long as we can perceive, through the new semantic pertinence-and so to speak in its denseness-the resistance of the words in their ordinary use and therefore their incompatibility at the level of a literal interpretation" (1984, p. ix). I wasn't sure-one doesn't know-if my semantic impertinence would yield insights into reality for readers, but it was a fertile image for me to think with. It provided a way to get at something about ethical possibility that I have found exceedingly hard to theorize as part of everyday life, what Arendt has called the "miracle of natality." I was particularly concerned with circumstances where people are caught, circumstances that in many senses seem to overdetermine their destinies.

In their masterful introduction, Kuan and Gron thematize key arguments of the collection as a whole, turning to particular articles in doing so. I will not try to replicate what they have already accomplished, but in what follows, I will visit specific contributions to explore how these have helped me to rethink, or think better, the arguments I outlined in the Moral Laboratories book.

\section{Miracles of Natality and the Treacheries of Moral Care}

Many of the papers, but especially Gron, Kuan and Taylor, take up a problem that I have tried to address: How do we consider situations in which people "are not only working with the odds, but in important ways against them-where the possible is pitted against the predictable?" How do we both notice and dignify efforts of the relatively powerless even as we document (without romantic hopes and Hollywood happy endings) how their lives unfold, often with many failures? And how might we consider the way that people make small or temporary gains, or shifts in the usual order of things, as "miracles"?

I turn to Janelle Taylor's paper first. Taylor juxtaposes three experimental spaces that she finds in her study of dementia and friendship: (1) most important, moral experiments, that is socially grounded interventions into everyday experiences of isolation and marginalization; (2) artistic experiments, including representational interventions into the public culture of media and fiction but more importantly, small scale and local engagements with art; and 3) more indirectly, even as a kind of foil, scientific experiments (especially as depicted in popular culture)— the ideal of a laboratory based research offering the (as yet deferred) promise of medical cure. Although she opens her paper with a discussion of the box office hit Still Alice, she foregrounds another, less visible kind of artistic space and aesthetics acts of a 
humbler sort, namely creative experiments involving people with dementia in the making and enjoyment of art.

In looking at the intersection of art and friendship she attends to what local community programs like "Meet me at the MOMA" offer as spaces that allow participants to "improvise new forms of social life." These programs, as taken up by some of the families and friends in her study, are registered by Taylor as "social and moral experiments" in how to stay engaged, socially, with others and in one's world, even for those with severe dementia. It is not only these practices and spaces of art that provide moral experiments, however. It is the participation in them as social acts, specifically with friends, that suggest a kind of moral experimentation in a much deeper sense. In participating with friends in activities like these, "friendship itself becomes a site of experimentation," Taylor tells us.

In exploring the moral experimentation of friendship itself, Taylor provides another way to understand what I also try to emphasize, how small scale activities and situations - say, a trip with friends to an art gallery - can create conditions for the emergence of new virtues. She is particularly interested in the kinds of virtues that may be demanded to keep a friendship going with someone who has dementia. Even such practices as "gossiping" — not the sort of thing one ordinarily associates with virtuous action-may be integral in helping friends "hold an individual in personhood." Taylor emphasizes the moral weight of what is so easily overlooked, little actions that can seem merely mundane, neither experimental nor particularly ethical (just some friends heading to the art gallery, or sitting around gossiping). This is moral work of the highest order, she insists, and it can demand strenuous efforts by friends. "At the most basic level," Taylor writes, "the commitment to keeping up relations of friendship in the face of the changes wrought by dementia is a fundamentally moral commitment.

Lone Gron's paper also insists on the moral weight of the small act in the face of daunting odds. She explores the elusive quality of transformation as a miracle, but a miracle that is intimately connected to minor everyday life events as well as an existential unpredictability, the elusiveness of lived experience. Drawing upon the phenomenologist, Waldenfels, Gron allows us into a world that is, on the one hand, all too predictable and ordinary-obesity, something that has now risen to epidemic proportions in Denmark. While there is, she notices, a widespread sense that "we know what obesity is," the people she has followed in her ethnographic fieldwork do not share this view. For them, it is quite mysterious why it is so difficult to lose this weight. They are haunted by it-it is both part of them and yet alien. In Waldenfel's sense, Gron tells us, obesity appears "as a haunting that exceeds one's grasp, one's capacities to know, to control and to will." Following Waldenfels, she describes obesity as a "demand to which one must respond."

What Gron is able to do with this idea of responsivity is to take something like "experimentation" and deepen it. The trope of the laboratory and the idea of experimentation (from the perspective of the experimenter) calls attention to the agentive side of life, the way that we are, or try to be, actors in our lives. But Gron shows us how experimentation may unfold in quite a different way-it may involve a kind of waiting and anticipating. According to the main protagonist of her article, Rita, it involves a shift from assuming the stance of the actor who can take control- 
the one who tries (through many weight loss schemes) to change things, to move the stone-to one who waits and anticipates. This might seem like a relinquishment of action altogether. Not so. Lone tells us that this is not "a passive or resting on the side" kind of waiting but an invested and demanding practice of acknowledging circumstances and facts while keeping a space open for the new, the miraculous to occur, and then having the courage to go for it whenever some potentiality lands on your doorstep."

In this collection, Gron offers one of the most serious challenges to my own depiction of the moral laboratory. While I have followed lives over time to notice the various ways that small actions are recognizable as elements of longer-term projects and aspirations (and this has been my way of thinking about the self, one with temporal depth), Gron makes different case for what the biographical and narrative self, the self lived over time, tells us about experiment and project. My informants have emphasized the moral acts of struggling, persevering, envincing strength to meet all odds, as central to ethical life. Everything may fail, of course. Life is not in your control. But still, struggling is ethically crucial. But Lone's protagonist, Rita, for all her many activities, voices something different. Perhaps it is learning how to wait, waiting in the right way, that is crucial.

Despite the very different ethnographic scenes that Taylor's and Gron's articles describe, there is a certain familiar resonance with the spaces of my own ethnography. All three of us attend to the dense interconnections of families and friends, intimate relationships that easily break, fragile bodies that are threatened but also threaten. These worlds seem far from real (i.e. science) laboratories, characterized by ordered arrangements designed for careful measurements, for predictions, for ruling out "noise." Scientific laboratories do seem to demand controlled environments that eliminate the vagaries of everyday life. And indeed, in the science laboratories investigated by Sharp and Svendsen et al., conditions are quite precisely controlled in ways we might expect. Even ontologically, things are in place. Pigs are pigs and research monkeys are simians, not humans. But in the moral laboratories that these science labs engender, much unravels. This is especially so for those humans most closely charged with care for the research animals. Here, ontological divides become troubled, or at least demand experimental trans-species traversing. By introducing the ethical dimensions of laboratory life - a moral laboratory that lives alongside the science lab-quite unprecedented and unruly elements appear that were not intended by the science experiments at all, ones that compel us to consider a kind of ontological natality.

The paper by Svendson et al. considers three distinct experimental and/or medical spaces, each with their own intricate ontological and ethical complexities. This includes non-human beings (piglets), humans who have lost qualities presumed vital for being human (as in the case with those suffering from severe dementia), or infants who are so medically precarious that it is sometimes unclear whether they should be seen as fully human. In what follows, I focus on the piglet research labs, since this case most dramatically exemplifies the ontological slipperiness of everyday care work. The authors note the ethical struggle humans have to find a way to properly care for and categorize beings who are not quite human, in the standard sense. For the laboratory workers in the piglet studies, being ethical means 
sometimes treating the piglets as animal-objects and sometimes as "agentive and suffering beings" who deserve protection, dignity and care. The authors ask: "how is worth practiced" in this kind of situation? It is practiced, they explain, not by settling on either the animal-as-object understanding nor on their human-like status, but finding a way to move between the two positions.

There is a deep resonance between these piglet researchers and those Sharp's paper considers (who work with research monkeys) which raise even more controversial questions about ethical research practices. Leslie Sharp vividly shows us how the ontological level questions are not only tied to ethical ones (indeed emerge most poignantly as ethical for the participating humans) but that these questions are raised in everyday ways, or, as Lesley puts it, through "quirky quotidian practices that go unmarked" in the care of animals in experimental laboratories. These come to light in particular in the everyday care provided by the laboratory workers who are closest to the animals. They are the ones who find themselves most provoked by ethical concerns. And "best care" practices that have arisen in experimentation with non-human primates also point toward the questionable and changeable status of animals vis a vis humans - at times they are "work objects" and "data points" but at other times, they are not only "wild animals" (who should have some of the comforts and life they could expect in the wild) but also small children, who deserve a playroom.

Sharp finds an intriguing entry point into this-the lab TV. Providing TV for primates to watch is now a standard part of best care practice. She shows us that a "lab TV is doubly moral: it evidences the 'humanness' of monkeys alongside the 'humane' qualities of human caretakers entwined in a 'double helix' of scientific domestication." In doing so, she also offers a glimpse into the world of the technicians who may live in close quarters with particular monkeys they come to know for years. They find themselves excluded from ordinary social life because many would find their work "immoral." They make close friends with one another and spend a great deal of their time at work- "the monkey room, then, is home." For them, the monkeys are also crucial actors in their lives: "just as lab techs domesticate captive macaques by providing them with quirky creature comforts" (e.g. Animal Planet reruns) "the monkeys in turn facilitate the domestication of the lab techs as the human caretakers of creatures whose days are numbered by the demands of experimental neuroscience."

Taken together, both Sharp and Svendsen et al. emphasize that for research lab workers, the human-non-human divide is not always an easy border to traverse and can sometimes generate moral incommensurabilities. How to balance, for example, the need to allow the animals to suffer (for the sake of good science and potential human lives) with the need to care for the animals as fellow suffering creatures? Laboratory workers find themselves confronted by an ontological incommensurability that is deeply connected to an ethical one, how to straddle the "existential affinity with the human" that treating them with worth calls for, while also treating them as a "tool for human health and potential" — as a "disease-object" that worth (in the form of alleviating future human suffering) also calls for?

Svendsen et al. and Sharp thus explore the blurred boundaries between moral laboratories (as trope) and the moral quandaries, ethical experimentation and 
cultivation of virtues that "real" labs instigate for the humans who create and especially implement them on a daily basis. Their articles not only call us to consider the role of (non human) animals in laboratory science. These authors emphasize how the specific moral troubles surrounding practices of animal experimentation speak to ontological/ethical concerns about what it means to be human and what beings, under what circumstances, qualify as worthy of care.

\section{The Materiality of the Moral Lab}

Another key attraction of the laboratory trope, from my perspective, is its obvious materiality. Real labs, at least as we commonly imagine them, are very much physical places, where everyday work is accomplished through all manner of complex and specialized machinery in spaces strictly cordoned off from ordinary life. Considering people's efforts and projects of everyday moral transformation with this kind of materiality in mind provoked another kind of semantic impertinence I found useful. Moral transformation easily sounds like some kind of internal act, working on one's emotions, or will, or the like. But this isn't the way that ethical work showed up in my fieldwork. It was always interpersonal, and embedded in everyday routines, including family rituals and squabbles. The kitchen table and the TV remote played privileged roles. To return to the exemplar I introduced earlier, a soccer field is not just a social space but also a physical one, whose materiality also provides the necessity and "tools" for experiment. It is not just rules of the game that require some experimental reinvention once a player in a wheelchair is inserted; there are physical demands to consider. Who will push the chair? What counts as a kick with a boy whose legs don't move? Is the wheelchair the same as a foot, in this instance? Can a wheelchair be propelled over the rough ground without toppling it over? While I might have called upon the many popular theories of materiality that especially science studies have cultivated (e.g. materialist ontologies or Latour inspired actor-network-theory), these struck me as too literal and, therefore, potentially detracting from the psychological complexity of biographical family lives I wanted to shore up.

Here again, the articles in this collection have helped me deepen my appreciation of the materiality of moral struggle. Every one of them, even those that do not think with the materiality of science laboratories, play with objects or the sensual material world in ways that can double as metaphorical and literal, all at once. Rita's "magic $200 \mathrm{lb}$," is not just flesh-the 200 extra pounds that define her as obese. They have a "magic" to them, for one can never be completely sure when or how they might melt off. If they are Rita's "big stone," that too, is not something one can just move by exerting all one's force, all one's will. In fact, Rita has found, willing doesn't work, contrary to all the advice of experts. And what about Rita's fertile garden, the one she lovingly grooms? This is a real garden surely, but it is impossible not to take this as a living breathing metaphor.

I have saved Teresa Kuan's paper for last. It has a great deal to say about natality, but it also makes an extended and intriguing case about materiality and ethics. She explores the juxtaposition between a picture of an unruly everyday world (a portrait 
I often paint in Moral Laboratories) and the space of controlled experiment (a real lab), and turns this portrait on its head. Her paper asks us to think in an opposite way. Everyday life is what is controlled, predictable, even frozen. Carefully controlled psychological laboratories (which mimic science labs in many respects) are where the unmannered and the unpredictable can be introduced. This vision of the inertness of ordinary family life, a repetitive reproduction of the status quo, is not only the perspective underlying the family therapists she explores but, of course, it was a perspective that often dominated traditional anthropology. However, it is rendered unfamiliar in the interventionist world of the disruptive family therapist. The task of the therapist, Kuan explains, is to bring the family system to life by infusing it with the kind of vital energy that transformation demands. For this to happen, the therapist must be willing to introduce experiments in family discomfort, ones that may be ethically unfair.

Kuan has quite a lot to say about the materiality of the lab set-up that this kind of practice relies upon but what I especially want to note here is how she connects this trope of the moral laboratory to "immanent vitality." She describes the family systems therapists as "relationship engineers"-working hard, as she puts it to "rearrange the small particles of family life." She is attentive to the connection between the "material infrastructure" in which these therapy sessions are arranged and their moral experimentation-for "family therapy is distinctive for its dramatic qualities." The dramatism of family therapy, Kuan suggests, might benefit from being seen in ways that challenge its own understandings-and perhaps those I bring to Moral Laboratories. I return to some themes that were more explicitly voiced in her original AAA paper than in this article, because she offered some provocations that are worth at least raising about the limits of humanism.

Family therapy could certainly be interpreted in humanist terms that foreground human interdependence, sociality, intentionality, sub-consciousness, and the like. But, when Kuan calls upon the importance of the material in situating these dramatic scenes, she asks us to consider something else. Might we also attend to the materiality of these therapy sessions, to what she calls the "vibrating world of subsocial life" that is inseparable from the very human acts of the therapists and family members? Kuan suggests, tantalizingly, some creative links between the complexity and unpredictability of human life (which I keep thinking about) and the unpredictable and dynamic features of material processes used in this kind of experimental therapy (e.g. the way they are produced via technology, to be viewed by an audience through one way mirrors). Although she does not foreground this argument in her article, one still hears the resonance of this line of thinking in the kind of vitalist materiality she calls upon when invoking the disturbing energy of these therapy sessions.

I have sometimes challenged Teresa Kuan about her post-humanism. Perhaps we will always disagree. But she finds an avenue for asking questions that I take to the heart, and in ways I would not have managed. She offers this query, very much in her vocabulary and with her images in mind (of vital energy), but one that speaks to my own attachment to a trope of experiment: "Would it be possible for anthropology to simultaneously conserve its critical energy and attend to the immanent vitality of the small and the ordinary?" 


\section{References}

Beardsley, Monroe

1962 The Metaphorical Twist. Philosophy and Phenomenological Research 22:293-307.

Ricoeur, Paul

1984 Time and Narrative, vol 1. Translated by K. McLaughlin and. Pellauer. Chicago: University of Chicago Press.

Ricoeur, Paul

2003 The Rule of Metaphor. London: Routledge Classics. 